(ISSN: 2610-9182)

\title{
Qualitative Exploration of Legal, Economic and Health Impacts of Covid-19 in Saudi Arabia
}

\author{
Yusuff Jelili Amuda ${ }^{1}$, Emna Chikhaoui ${ }^{1}$, Shafiqul Hassan ${ }^{1}$, Mohsin Dhali ${ }^{1 *}$ \\ ${ }^{1}$ College of Law, Prince Sultan University, Rafha Street, Riyadh 11586, Saudi Arabia.
}

\begin{abstract}
Since the outbreak of COVID-19, several researches have been conducted in different parts of the world, including Saudi Arabia. However, there is little focus of attention on qualitative exploration of the impacts of COVID-19 in the context of Saudi Arabia. The primary objective of this study was to explore the opinions of legal, economic, and medical experts pertaining to the impacts of COVID-19. The methodology employed in this paper was a qualitative research design. The data was collected with a specific focus on the use of an in-depth interview. Fifteen (15) participants among the legal, economic, and medical experts were finally used for the interview among the targeted participants. In order to analyze the data, different themes were generated from the transcribed interviews, which were: Overview of COVID-19, legal, economic, health impacts. The finding of the study revealed that the current pandemic of Covid-19 has multidimensional impacts in Saudi Arabia. The pandemic has negative impact not only on the social and economic areas but also on the legal sphere. Social and economic impacts of the Covid-19 increase the inequality, discrimination, unemployment, deprivation of usual education, and disruption in business activities. The findings further indicated that the legal impact of COVID-19 has been mentioned in the aspect of the inability to perform contracts that have the potential to trigger default or force majeure provisions leading to litigation or reconciliation. In addition, the participants also acknowledged the health impact of COVID-19 in causing anxiety, suffering from illness, loneliness, depression, and causing death, among others. If not properly addressed through effective measures and policy, the impact of the COVID-19 on the legal, economic, and health spheres would have severe consequences. Therefore, it is recommended that all the stakeholders, especially the government of Saudi Arabia should effectively and efficiently address the legal, economic, and health impacts of COVID-19.
\end{abstract}

\section{Keywords:}

COVID-19;

Legal, Economic and Health Impacts;

Force Majeure;

Saudi Arabia.

Article History:

Received: $\quad 20 \quad$ September 2021

Revised: $\quad 18 \quad$ November 2021

Accepted: 06 December 2021

Published: 18 December 2021

\section{1- Introduction}

There are overwhelming studies on COVID-19 in different parts of the world, and most of the studies were theoretical or quantitative empirical studies in nature [1,2]. There is less focus of attention in exploring the impacts of COVID-19 using a qualitative method by conducting an in-depth interview among the target participants in Saudi Arabia. This paper attempts to empirically explore the triadic impacts of COVID-19 among legal, economic, and health experts in the context of Saudi Arabia. The study is necessary and motivated to be carried out in addressing the negative consequences in the country, especially it raises legal concern regarding parties' contracts; it affects socio-economic development of the country despite the fact that the country has been striving to attain vision 2030 and it puts the health workers at high risk of contagious nature of Covid-19.

*CONTACT: mdhali@psu.edu.sa

DOI: http://dx.doi.org/10.28991/esj-2022-SPER-01

(C) 2022 by the authors. Licensee ESJ, Italy. This is an open access article under the terms and conditions of the Creative Commons Attribution (CC-BY) license (https://creativecommons.org/licenses/by/4.0/). 
The outbreak of the COVID-19 pandemic and its contagious spread on the 11th March 2020 from Wuhan in China to different parts of the world, is considered as clinical and pathogenic respiratory infections that became viral in both developed and developing countries [3-5]. Notably, throughout the world, including Saudi Arabia, the pandemic of COVID-19 is felt, and there have been strict measures in curtailing its spread. As a result, there was the suspension of different national and international activities such as traveling, business activities etc. [6]. This scenario is also applicable in the context of Saudi Arabia [7]. Undoubtedly, the aforementioned measures are in line with the international approach of the World Health Organization (WHO), specifically in making restrictive physical contact or social interaction that may eventually lead to the spread of the virus as literature contends [1, 2]. It is not disagreeable to posit that the multifarious measures in curbing the pandemic of COVID-19 may undoubtedly affect different spheres of society, such as business activities, suppliers, and labor in general [8].

Onwards, as part of the effort in curtailing the menace of COVID-19, several proactive steps and measures are being imposed by the government of Saudi Arabia, such as making restrictions on both national and international traveling. Similarly, those who had just arrived from foreign countries were being quarantined to curb the further spread of the virus. In addition, the government of Saudi Arabia has been proactive, especially with the suspension of pilgrimage and tourist activities in the country [9]. Also, there is enlightenment and dissemination of information regarding healthcare, and there was a declaration of stay-at-home-order and avoidance of more mass gathering as part of the efforts to mitigate the spread of COVID-19 but with the exception of security military, and healthcare workers [6].

Onwards, indeed, the legal framework also has a significant role in curtailing the spread of COVID-19 in the country. The current legal framework in Saudi Arabia is based on Shariah or Islamic law and it is regarded as a reflection or manifestation of the country's religious and socio-cultural values and settings [10]. In 2018, the government released legal principles and precedents whereby Shariah was regarded as a supplement to the regulations [10]. Notably, Islamic law is considered a major source of family, criminal, commercial and contract laws. More specifically, the commercial and contract activities are guided by Islamic law whereby the Board of Grievances and Special Tribunals were established to find ways of circumnavigating the restive aspect of Islamic law. Therefore, the extent of the spread of pandemics attracts efforts to address legal issues from different perspectives. There are various aspects of legal issues relating to COVID-19, and among others are parties' contracts, legal consequences of bankruptcy. Prior to the pandemic of COVID-19, previous studies have clamored for the reform of the legal system due to the need to holistically address the challenges of the 21st Century in Saudi Arabia [11, 12]. However, the need for this reform emanates from internal crisis within the kingdom, and more specifically, legal reform in business and commercial activities as identified in the early studies have resurfaced in the recent time with the outbreak of COVID-19, which calls for the legal reform that will accommodate the occurrence of eventualities such as the outbreak of COVID-19 [13]. Similarly, previous studies have advocated for the reform of Islamic Commercial Law towards economic development in the country, which is in line with the advocacy of the recent literature that the labor market should address the economic challenge of COVID19 [8]. More importantly, the legal aspect of COVID-19 needs to be exhausted in the aspect of business and commercial activities in the country during this critical period of COVID-19 because several previous studies have advocated for the reform of the legal system towards consideration of values and socio-cultural realities of the kingdom.

Furthermore, before the outbreak of COVID-19, Saudi Arabia has been moving rapidly towards the actualization of Vision 2030, specifically, towards economic and social developments in the country. For instance, a report has shown that several projects worth USD 1.6 trillion are underway, and more importantly, there are Red Sea Development and NEOM projects. But the outbreak of COVID-19 has put a stop to most developmental projects in the country, and priority has been given to how to curtail the pandemic. Moreover, many companies in Saudi Arabia have been operating business activities while other ones may be new in the country, and the operations of different companies that may not be familiar with the legal operation may even be more affected by the pandemic of COVID-19 in the country. It has been asserted that there would be scarcity of job opportunities; hence, traveling abroad, especially to Saudi Arabia, will soon be difficult due to the socio-economic implications or consequences of the COVID-19. The country's socio-economic impact of COVID-19 is perplexing because it affects all facets of human endeavors. The current action being taken in most countries now can be considered as short-term and serious fiscal socio-economic recovery in the country is paramount to be considered a long-term policy direction. It has been acknowledged that technology and Internet connectivity plays a significant role in fostering education, telemedicine, health information, and, more essentially, overall economic activity during COVID-19.

Further still, coronavirus, otherwise known as COVID-19, has posed a significant challenge to global health. World Health Organization (WHO) has been making an effort to address any virus that threatens the health of the entire world including the ongoing COVID-19 [14]. Nonetheless, the outbreak of COVID-19 posed a big shock even to the World Health Organization (WHO). Undeniably, COVID-19 is regarded as an infection that eventually causes abnormal respiratory system, specifically shortness of breath, dry cough and fever as literature posits [1]. It is not disagreeable that the virus is easily transmitted through contact from one person to another as literature contends [2]. The Arab world, 
including Saudi Arabia, is not left untouched by the threat of the pandemic as literature explicates [15]. More specifically, as of June 2020, Hilton reported that Saudi Arabia had over one hundred thousand cases of COVID-19 [16].

It is important to note that, health and welfare of the citizens are essential indicators of development in different parts of the world, including Saudi Arabia. Undoubtedly, COVID-19 has a significant negative impact on the medical profession or healthcare industry, even in Saudi Arabia. Generally, COVID-19 has a negative impact on an individual's health and his living condition. As a result of this, the experts have emphatically stressed the need for personal hygiene, self-isolation, and social distancing because it is a respiratory syndrome [17]. According to a report made by United Nations (2020), it was stressed that $70 \%$ of women are in the health workforce globally, and as a result of this, it exposes them to the pitiable risk of getting infected with the coronavirus. Saudi Arabia has been trying to encourage women's involvement in the workforce in the country. In addition, at the international level, there has been agitation for gender equality, especially by addressing the problem of poverty and vulnerability to discrimination against women for their participation in the workforce remained a great concern since a few decades ago. There is similar advocacy for gender equality in Saudi Arabia by allowing women's participation in the workforce. The preceding has explained the legal, economic, and health impacts of COVID-19 in the context of Saudi. Therefore, it is essential to say that there is a central research question guiding the paper, which states thus: How do the citizens perceive the impacts of the current pandemic of COVID-19-on legal, economic, and medical spheres in Saudi Arabia?

\section{2- Research Methodology}

This part presents the methodology employed in this study. Five steps were involved as part of the qualitative methodology used in this study which are as follows: Phenomenon (i.e., Covid-19), sampling (participants), data collection (an In-depth interview), data analysis (generated themes) \& adaption with the central research question (CRQ) and discussion of findings. Each of these is explained in the subsequent paragraphs. Qualitative method was used by conducting an in-depth interview among the participants for the study. Literature posits that interview is an integral part of survey research design in collecting data for particular research [6].

First, the phenomenon of Covid-19 is explored in the context of Saudi Arabia. A qualitative methodology has different paradigms. Hence, this study uses a holistic-inductive paradigm with a specific focus on the phenomenological approach. This enables the researchers to explore the phenomena of Covid-19 from legal, economic, and health aspects. This is necessary because the complexity of COVID-19 requires an investigation into this scenario in order to curtail the different negative impacts of the pandemic in the context of Saudi Arabia. Nonetheless, the research design used in this study was meant to consolidate the process of the interview guide for the collection of data and analysis of the data. Hence, it can be inferably said that the qualitative design is context-specific in the sense that it is limited to specific cities of Saudi Arabia.

Second, the participants selected for the study were not random and probabilistically selected among economic, medical/healthcare, and legal experts in selected cities in Saudi Arabia, namely: Riyadh, Madinah, Jeddah, Dammam, and Qatif. Thereby, a total number of twenty-one (21) participants was initially scheduled for the interview. However, only fifteen (15) participants' responses for the in-depth interview were used for the final analysis. This study was carried out with full knowledge and understanding of the participants among legal, economic, and health experts involved directly or indirectly with the phenomenon of Covid-19 in Saudi Arabia.

Third, regarding data collection, an in-depth interview served as an instrument for data collection among the selected participants for the study in the country. The interview guide covered different factors, namely: COVID-19, Legal, economic and health spheres in Saudi Arabia.

Fourth, data analysis was carried out from generated themes and it related to the adaption of the central research question (CRQ). More specifically, the interview questions through which themes were generated were done inductively from the exploration of available materials (data) instead of using a priori theories for the current issue like Covid-19. The central research question was undoubtedly used from which interview questions were generated to guide the indepth interview process. In order to analyze the data collected from the interview, different elements were considered: identify codes/themes, regroup the codes to develop the concept, identify higher-order commonalities within concepts to illustrate a category, and link the connection between the categories, and investigate the concepts. Then, relevant themes generated from the interview were used to analyze the interview, which was regarded as a discourse unit (D.U.).

Fifth, the data obtained through the interview was transcribed, and the data analysis was carried out by utilizing the narrative-style genre. Based on the interview as an integral part of a qualitative methodology, multiple responses from real-life experiences of the participants with Covid-19 in the context of Saudi Arabia were explicitly discussed. Table 1 shows participants for the interview, and the Figure 1 shows the flowchart of the qualitative research methodology employed in this study. 
Table 1. Participants for Interview

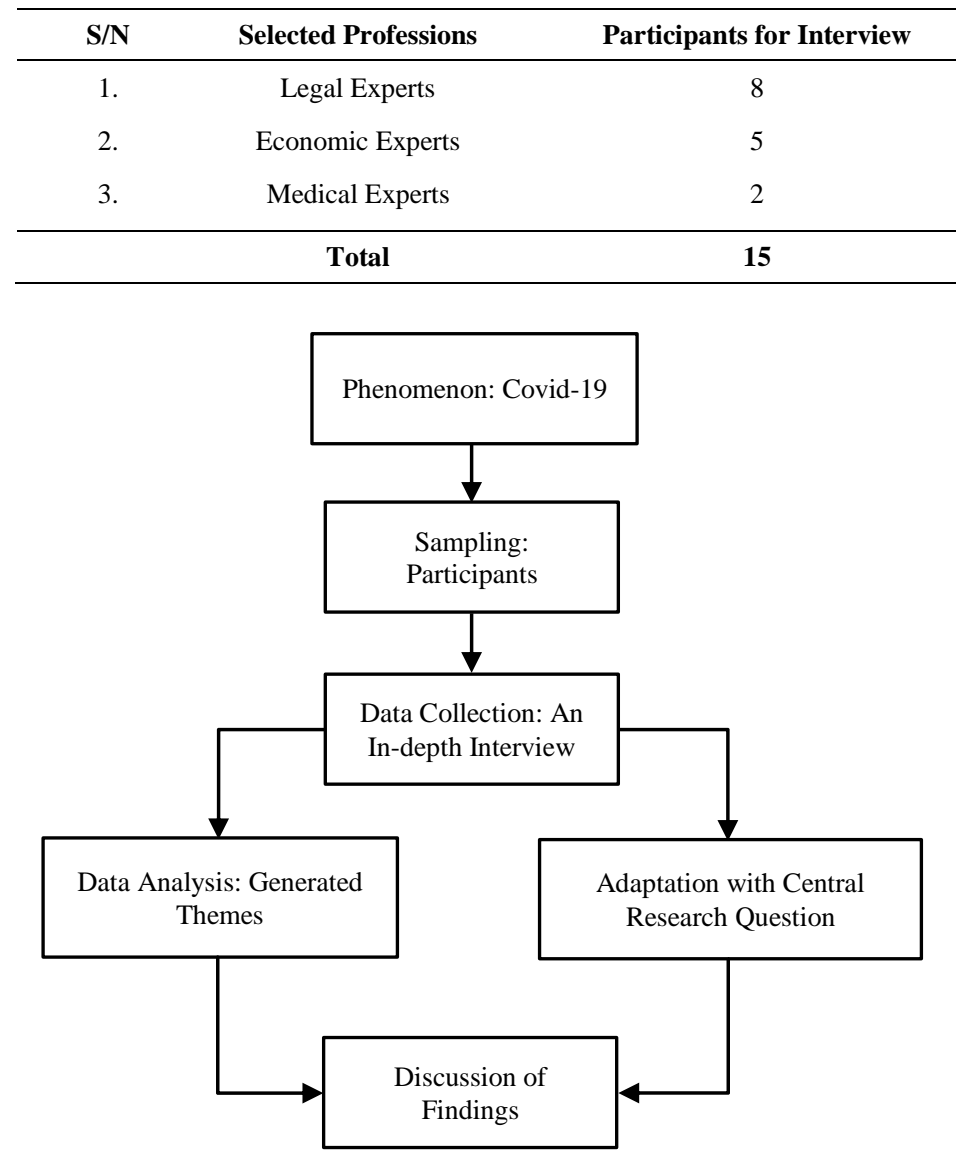

Figure 1. Flowchart of Qualitative Research Methodology employed in this study

\section{3- Result}

This part presents the findings relating to the Central Research Question (CRQ), which states thus: "How do the citizens perceive the impacts of the current pandemic of COVID-19 based on legal, socio-economic and health medical spheres in Saudi Arabia? The qualitative data analysis with a specific focus on an in-depth interview identified various codes/themes. The opinions of legal, economic, and medical experts were sought through the conduct of the interview pertaining to the COVID-19 in the context of Saudi Arabia. Discourse units (1-15) were responses obtained from legal, economic, and medical/health experts with respect to their perceptions on the impact of COVID-19 in the context of Saudi Arabia. More specifically, discourse units (D.U. 1-8) were from legal experts; D.U. 9-13 were from economic experts while D.U. 14-15 were from medical experts. Each of the findings in presented under various discourse units (D.U.).

\section{3-1-Interview Responses on Overview of Coronavirus (COVID-19) in Saudi Arabia}

The response from the first interviewee (discourse unit-D.U.1) regarding COVID-19 stated it as "an infectious airborne virus that is declared as a global pandemic in March 2020". According to the third interviewee (i.e., legal expert) (discourse unit-D.U. 3), "COVID-19 is "a virus affecting the human respiratory system". The fourth interviewee (discourse unit-D.U. 4), COVID-19 is considered as "A virus, dangerous one because of how quick it moves and goes". In addition, it is mentioned that, "The citizens are totally aware of the damages COVID-19 costs the country, and it's because of the government communication and dissemination of information in curtailing it" (D.U. 4). Based on the response obtained from interviewee (D.U. 5) on COVID-19, "It is regarded as a virus that causes illness ranging from the common cold to more severe diseases and most causes started to appear in Wuhan, China. The virus can be spread from one infected person to another through close contact without protection (D.U. 5). Onwards, the sixth interviewee (D.U. 6) stated that "COVID-19 is the acronym for the Coronavirus disease, which emerged in China in 2019. This virus is part of a family of viruses called the corona, meaning crown as it has its shape. It is a deadly virus, especially for the elders. It causes shortness of breath, loss of smell and taste, and fever. The COVID-19 became a pandemic affecting an international sanitary and economic crisis". "The seventh interviewee (D.U. 7) among the legal experts considered COVID-19 as, "It is a virus which causes fatal flue transformed from human-to-human so quickly". According to the interviewee (D.U. 8), COVID-19 is a virus that spreads quickly through contact with the mouth, nose, and eyes and affects your respiratory system. 
Furthermore, an interviewee (D.U. 9) regards COVID-19 as "A viral infection that spreads easily through droplets of saliva and mucus from an infected person". The interviewee (D.U. 10) considers COVID-19 as "Viruses that attack people to the virus which will affect your respiratory system and if it is not treated and it will have a deadly impact". Interviewee (D.U. 11) noted that, "Coronavirus (COVID-19) is a new disease, and our understanding of the virus that causes it continues to evolve. It was first detected in China and has now been detected in over 100 countries, including the United States". Similarly, the interviewee (D. U. 12) contends that "COVID-19 is a respiratory disease which was first observed in Wuhan Province of China in December 2019. It is from the family of Coronaviruses and also goes by the name of Novel Coronavirus. Even if it is less deadly compared to other coronaviruses, it is more contagious compared to others. During 2020, it spread to almost all countries of the world, causing curfew and lockdowns in most of the countries for several months at a time. Currently, most countries, especially of Europe, are witnessing $2^{\text {nd }}$ or $3^{\text {rd }}$ wave of COVID-19 spread".

Moreover, another participant in the interview (D.U. 13) explained that COVID-19 is mentioned as, "It is a pandemic strain of SARS VIRUS that is contagious through a touch with the virus on the eyes, nose, and mouth". According to D.U. 14, a medical doctor contends that "COVID-19 is the virus that came in 2019. COVID-19 started in the city of Wuhan in China. It is a deadly virus; the most dangerous virus appears in the $21^{\text {st }}$ Century. This virus caused high rate of death in the world and impacted on the economy of many countries". Another medical expert as an interviewee (D.U. 15) considers COVID-19 thus: "It is a novel coronavirus, and the World Health Organization (WHO) designated the disease, COVID-19 which stands for coronavirus disease emerged in 2019. Direct person transmission is the primary means of SARS COV-2 transmission, mainly through closed range contact via respiratory droplets".

Furthermore, the interviewees have responded to the impacts of COVID-19 among citizens in the context of Saudi Arabia. More specifically, according to D.U. 4 about the impact of COVID-19, "The lockdown affected the people by letting them away from others and isolated them, and it is tough since Saudis are very strong when it comes to social life and relationships". Based on D.U. 5, the impact of COVID-19 is mentioned thus, "As a result of the lockdown, people reduced their social gatherings, events, and tend to be less social due to the social distancing and the quick spread of the virus. According to one of the legal experts, various impacts of COVID-19 were mentioned thus, "Confinement; working and education online; stress and anxiety; reliance and trust on the ministry of health and the ministry of commerce; feeling of national pride of the management of the crisis".

\section{3-2-Interview Responses of Legal Impact of COVID-19}

There were eight (8) discourse units (D.U.) generated from the interview conducted among the legal experts. It is reiterated that, "The legal impact of COVID-19 will include the inability to perform contracts triggering events of default and/or force majeure provisions. We may see a rise in breach of contracts leading to litigation or settlements/ reconciliation" (D.U. 1).

It is further affirmed that "The KSA government has done a great job at limiting the spread of COVID-19 within the KSA. As such, I consider the impact is an only minor disruption in daily life such as the need to wear masks and maintain social distance" (D.U. 3). It is further explained that "Initially the legal impact was significant because parties to contracts were exercising force majeure clauses. There has also been a slowdown in transnational work but so far not transactions I am working on have been cancelled because of COVID-19” (D.U. 4). The response from D.U. 5 regarding the legal impact of COVID-19, it is mentioned that "The contracting parties may experience difficulty in performing their obligations under the contract due to the pandemic". In addition, "COVID-19 is giving birth to a new style of living, new rules should emerge" (D.U. 6). The interviewee (D.U. 7) says: "The Saudi government mostly controls the COVID19 by confirming social distance ensured by curfews and special laws. Law enforcement agencies are working day and night to improve the situation". It is reiterated in D.U. 9 that, "The legal impact was effective as people complied with COVID-19 protocols, full enforcement of law and curfew was effective".

Onwards, D.U. 10 posits that “...If people do not obey the rule, for example, not wearing a mask, gathering more than the certain number of people, no social distancing in the shop where the authority can heavily find them". It is further emphasized that, by the interviewee (D.U. 12), "Definitely legal aspects of life in Saudi Arabia has changed. And in case of any such emergency, many personal liberties were restricted during the pandemic. People were not allowed to leave their houses during the curfew, and peoples' mobility was restricted. Government's rights over citizens have expanded, and now it has more rights to punish violators of certain regulations related to COVID-19". It is stressed by the participant (D.U. 13) that the legal impact of COVID-19 is related that, "This is on companies who have to lay-off people". Concerning the legal impact of COVID-19 in Saudi Arabia, a medical expert as an interviewee (D.U.14) posited that, "I do not have the expertise to offer any significant contributions to the legal ramifications of the disease. It certainly slowed down legal proceedings, as would be expected in any global pandemic". Since there were 8 legal experts chosen for this research, the histogram shows a high need for legal expertise in addressing the short-term and long-term legal impact of COVID-19 in Saudi Arabia, as shown in the mean and standard deviation of histogram (M=4.50; Std. Deviation=2.449). 


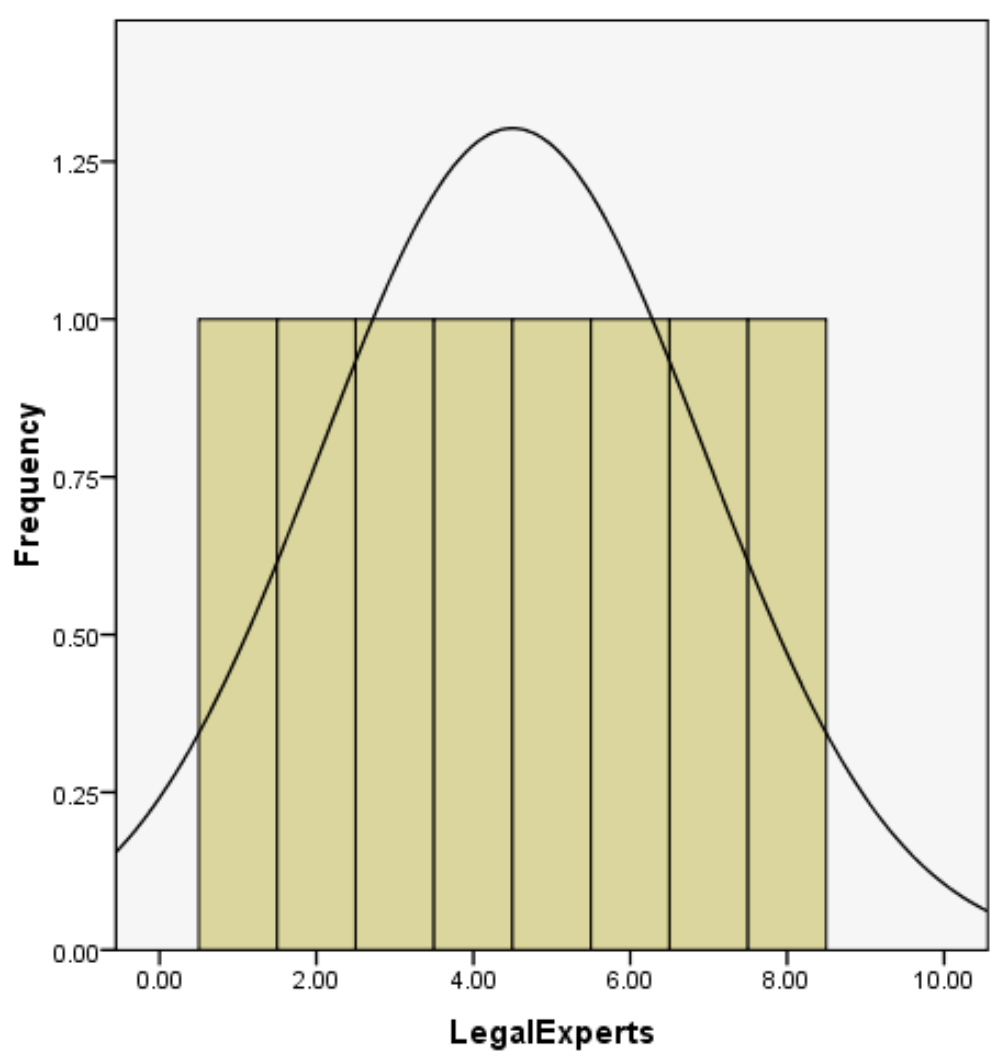

Mean $=4.50$

Std. Dev. $=2.449$

$\mathrm{N}=8$

Figure 2. Legal Impact of COVID-19

\section{3-3-Interview Responses of Economic Impact of COVID-19}

This part explains the economic impact of COVID-19. It is noted that "COVID-19 impacted the citizens of Saudi Arabia in different ways, such as socially, economically, and financially. It changed the way people function in society, affected their economy, financial status and health". In addition, COVID-19's socio-economic impact in Saudi Arabia could probably impact the unemployment rate, given that it will result in a big hit to certain businesses that will have an impact in mass lay-offs. It will also have a bigger impact on women who will need to cater to their children's homeschooling needs as well as play multiple roles. According to the interviewee (DU. 3), it is posited that, "The KSA government has done a great job at limiting the spread of COVID-19 within the KSA. As such, I consider the impact is only minor disruption in daily life, such as the need to wear masks and maintain social distance. Economically, all countries worldwide have been affected, but again, I believe because of the opportunities arising from Vision 2030, the KSA will return to economic growth this year" (D.U.3). It is further mentioned that economically, the interviewee (D.U. 4) posited that, "I believe it somehow affected business Tax and Zakat". It defiantly cost a big loss either for business or social events since Social distance is a must with this virus (D.U. 4). Regarding the medical impact of COVID-19, It is noted that "Is not hidden to anyone medical field was on top of the affected fields, hospitals and ICU is a word everyone used to hear daily during COVID-19. It impacts medical field a lot either sources or money".

Furthermore, D.U. 5 states that "The economic impact of COVID-19 and the plunge in oil process has affected the position of the government finances in Saudi Arabia. However, the KSA government has taken major economic initiatives to combat the COVID-19, such as supporting private sectors mostly affected by the pandemic". Suppression of old jobs, online relationship, virtual etc. (D.U. 6). Notably, D.U. 7 posits that "It has tremendous socio-economic impacts in Saudi Arabia. Several business entities have closed their operations in Saudi Arabia or reduced employees in all sectors. Huge numbers of foreigners have been leaving KSA, which have also significant impacts on the social, economic and educational activities". The interviewee (D.U. 8) on the economic impact of posits that, "The current pandemic has definitely had a detrimental impact on the economy particularly affecting businesses, SMEs, startups and working parents having to deal with homeschooling.

Based on the D.U. 8, it is noted that the economic impact of COVID-19 is related to "Loss of business, closure of small businesses; Social - increase of poverty for some families due to loss of job, increase of abuse in homes, family breakdown etc.". Pertaining to the impact of COVID-19, D. U. 9 contends that, "Loss of income, as most businesses were shut down. There was exodus of experts due to low economic activities. This could open up more job opportunities for Saudi citizens in the aftermath of the pandemic". In addition, interviewee (D.U. 9) contends that, COVID-19 is regarded as, "It has negative shock on businesses and household consumptions". Further still, it is regarded that, "It has negatively affected socio-economic activities especially hajj and foreign exchange that comes along with it from different 
countries" (D.U.9). Concerning the economic impact of the COVID-19, the participant in the interview (D.U. 11) said that, "Eating habits are impacted during quarantine by reducing available goods, lack of the accessibility of food, grocery store limited opening hours, and consuming unhealthy food". It is further noted that: For information on the economic recovery scheme put in place by the Saudi government to address the impact of the COVID-19 pandemic on the Saudi economy, consult the website of the Ministry of Finance. Further details can be sourced on the dedicated page of KPMG's website. For a general overview of the key economic policy responses to the COVID-19 outbreak (fiscal, monetary, and macroeconomic) taken by the Saudi government to limit the socio-economic impact of the COVID-19 pandemic, please consult the section dedicated to Saudi Arabia in the IMF's Policy Tracker platform. The economy of Saudi Arabia also suffered a heavy impact; a budget deficit of 9 billion US dollars was reported in the first quarter of 2020 caused by the decline in oil prices and the economic effects of the pandemic (D.U. 11).

Apart from the foregoing, another socio-economic impact of COVID-19 in Saudi Arabia, it is mentioned by one of the participants in the interview (D.U. 12) thus: "Economy suffered in Saudi Arabia due to two main reasons both are related to COVID-19. Firstly, restrictions on operation of businesses during curfew had reduced income of many business owners and their employees. Thus, many people felt reduction in their sources of income. Secondly, from a macroeconomic perspective, the Saudi government and its companies related to Petro-chemical industry have also suffered reduction in revenue due to sharp decline in the price of petroleum at the international level. Also, because people had less economic activity, government income coming from VAT has been reduced. Socially, people felt the negative impact of COVID-19 due to the requirement of social distancing and self-isolation. Staying at home for long hours and not socializing with others have negative impact on people's personal happiness. Children also got too bored due to a long period of staying at home and online classes could not replace the full benefit of traditional classes both in terms of their quality and social interaction needed for children's personal development".

It is further asserted that the socio-economic impact of COVID-19 is expressed thus, "The overall impact is devastating" (D.U. 13). Virus of COVID-19 instilling fear in the citizens and the issue of social distancing, most of the companies are closed and suspended Umrah to the House of God along with workers lost their jobs (D.U. 14). Furthermore, one of the interviewees posited that "The restrictions on travel and lockdown were an absolute necessity, but such large measures are bound to place limitations on socio-economic growth". The restrictions of travel, tourism, and movement of the population meant that businesses were placed under immense strain. Some businesses might take longer than others to recover and it may require additional support from the public as well as the private sector. The global pandemic also impacted global trade, which deals with business transactions as the entire world grappled with this vicious and aggressive virus weakening havoc along its path.

Moreover, D.U. 7 indicates the impacts of COVID-19 thus, "It has a great impact on education, business, and profession in private and government sectors". Indeed, D.U. 9 added that "For students, most were able to pass courses that they would not ordinarily pass as monitoring online exams was quite difficult at the start of the pandemic". Based on (D. U. 12), the different impacts of COVID-19 among citizens in Saudi Arabia is mentioned by a participant (D.U. thus, "As in any other country ( 1 r, COVID-19 had a serious impact in the life of people living in Saudi Arabia. Social lives were disrupted, and many aspects of the economy were also impacted by the pandemic caused by the disease. It is no longer allowed to have large gatherings; many small businesses have suffered economically because they had to lock down for several months. Some types of businesses are still not functioning fully. Schools are still in distance learning mode, and many students and parents are not very comfortable with the quality of such education". Discourse Unit 13 also mentioned the impact of COVID-19 as an economic impact. Based on the responses from the participants in the interview, 5 economic experts were selected. Histogram showed a high need for economic expertise in addressing the short-term and long-term economic impact of COVID-19 in Saudi Arabia, as shown in the mean and standard deviation of histogram (M=3.00; Std. Deviation=1.581).

\section{3-4-Interview Responses of Medical/Health Impact of COVID-19}

The medical impact of COVID-19 could include pressure on the healthcare system, burnout of healthcare professionals, and increased costs in the healthcare sector. Similarly, based on the responses obtained from the first interviewee (discourse unit-D.U. 1), it is noted that the KSA government is also doing a fantastic job in terms of rolling out vaccinations. The medical impact is therefore minimal" (D.U. 3). Based on D.U. 5, COVID-19 has impacted positively, whereas the Ministry of Health took all necessary precautionary measures to prevent the spread of the pandemic of COVID-19 such as the allocation of many hospitals and schools to treat the patients. The KSA government and private sectors combined developed and launched approximately COVID-19 apps that provide health care services". Furthermore, the interviewee (D.U. 6) posits that, "Focus on the new disease, postponing non-urgent surgeries, organization of new equipment for COVID-19, more beds etc." Based on D.U. 7, the medical impact is considered as "It has been causing huge damages in the human body; a lot of lives have been lost and many people have been suffering from serious permanent and temporary physical injuries. In fact, entire civilization is in great threat to their survival". 


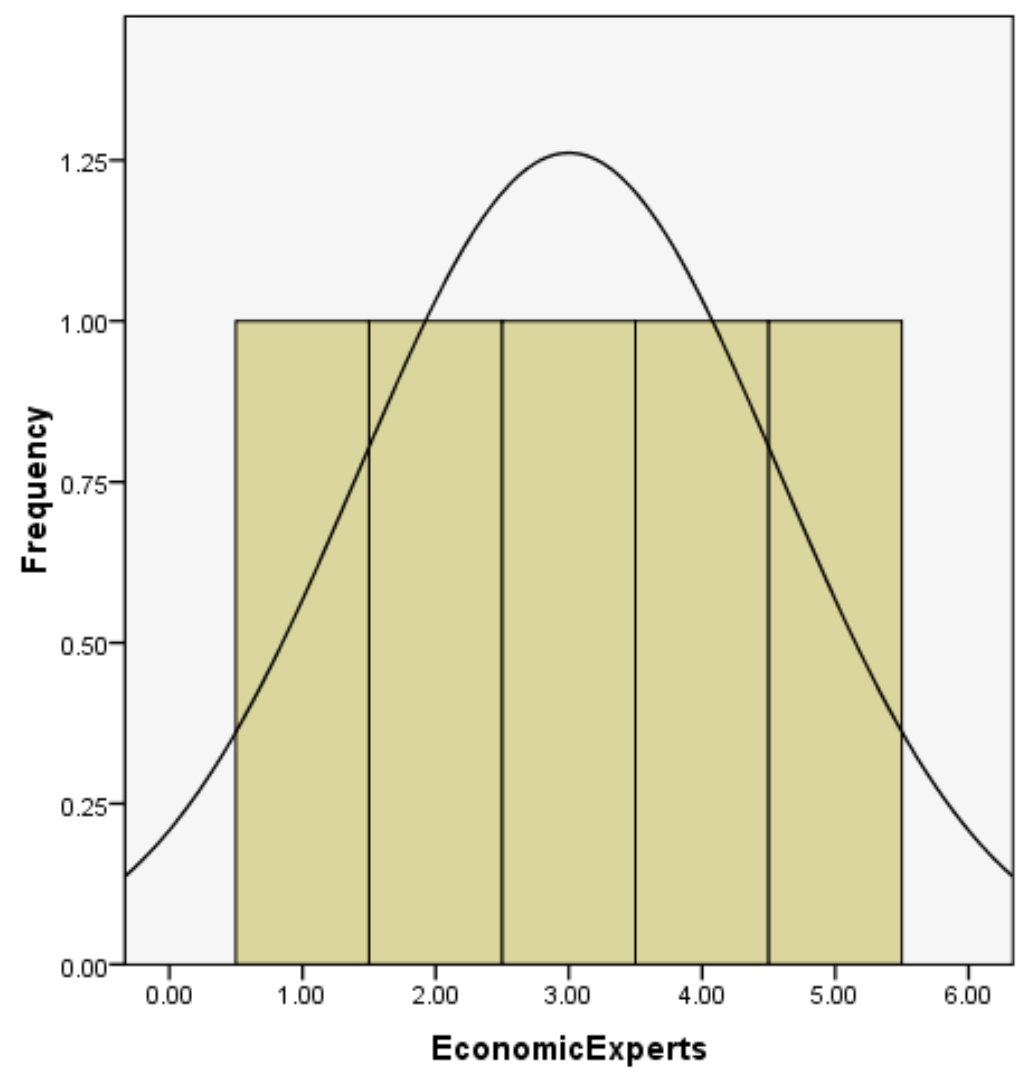

Mean $=3.00$

Std. Dev. $=1.581$

Figure 3. Economic Impact of COVID-19

The participant in the interview (D.U. 8) concerning the health impact of COVID-19 posits that, "Aside from the direct consequences of dealing with the virus, patients suffering from other illnesses have possibly had to delay treatment and less resources attributed to other diseases such as mental health - worry of catching the disease, isolation of adults and children, lack of socialization". Concerning the health impact of COVID-19, D.U. 9 contends that "Some people may suffer loneliness and depression as social gathering and outdoor activities were prohibited". The medical sphere was affected by an unprecedented number of patients in ICU and other services. However, looking back on the last 10 months, the country's leadership has managed to mitigate the impact by enforcing an early lockdown, introducing preventative measures from the beginning, and blocking travel, all of which I believe contributed to supporting the economy and lowering the number of cases".

Onwards, based on D.U. 9, it is mentioned that "Government medical support to COVID-19 has been excellent. Home services to citizens and medical palliatives have been provided". The respondent (D.U. 10) contends that the health impact of COVID-19 "Depends on their level of health risks and immune system". In addition, it is observed with regards to the medical impact that, "shortage of front liners such as nurses and medical practitioners". Regarding the precautionary measures against COVID-19 in Saudi, the interviewee (D.U. 11) posits, "In response to the COVID-19 pandemic, the government of the Kingdom of Saudi Arabia implemented a series of measures to limit the spread of COVID-19, including imposing nationwide curfews (reaching 24 hours in certain cities); suspending outbound, inbound, and in-Kingdom travel; and prohibiting physical attendance by employees at workplaces in both the private and public sectors (with certain exempted sectors)". In addition, Pharmacists helped to protect the public from COVID-19 pandemic disease by participating in various initiatives, including health education and promotion, medication dispensing, medication reconciliation, medication and patient counseling, training for self-management in the current outbreak, and emergency preparedness (D.U. 11).

Regarding the medical impact of COVID-19 in Saudi Arabia, the respondent(D.U. 12) :posits that "In terms of medial impact COVID-19 may have had both positive and negative ones. The negative impact is obvious since the spreading of any disease will cause a lot of suffering in any country's citizens and will cause an increase in dead tools. At times of COVID-19 spread pick, many hospitals were stretched to their limits and felt a shortage of beds and medical equipment to treat the COVID-19 patients. However, the good side is the improvement of hygiene both in hospitals and peoples' daily activities. Hospitals and medical clinics now pay more attention to the sterility of their premises, and people have started paying better attention to their personal hygiene. At the end, this will result in reduction in the spread of COVID-19 and other infectious diseases (D.U. 12). 
Onwards, it is reiterated that, as part of the health impact of COVID-19 that, "Mental stress, chronic mental problems to retain focus" (D.U.13). According to a medical expert (D.U. 14), it is posited that "COVID-19 impacted the health of the population given the highly contagious nature of the virus, but the initial lockdown significantly curbed the spread. The population demographic had a positive role to play in the severity and mortality rates associated with the disease. It restricted the movement of the population both within the nation as well as across international borders". Onwards, the medical field was pushed to its limits. But one of the most positive aspects was that personal protective equipment was adequate during the entirety of the surge. As in any pandemic, it helps expose the flaws in any system and provides an opportunity to grow. Healthcare sometimes and resources needed to be redirected in areas with a high number of cases, and more centers needed to take up the responsibility of caring for COVID-19 patients. In my opinion, most centers successfully rose to the challenge". Discourse Unit 5 mentioned stress and anxiety, while D.U 13 mentioned mental stress as an integral impact of COVID-19. In a nutshell, the preceding explanations have shown the participants' responses pertaining to the legal, economic, and health impact of COVID-19. It should be reiterated that two medical experts were selected for the interview, Histogram showed that there was a high need to address the medical impact of COVID-19 in Saudi Arabia as shown in the mean and standard deviation of histogram $(M=1.50 ;$ Std. Deviation=0.707).

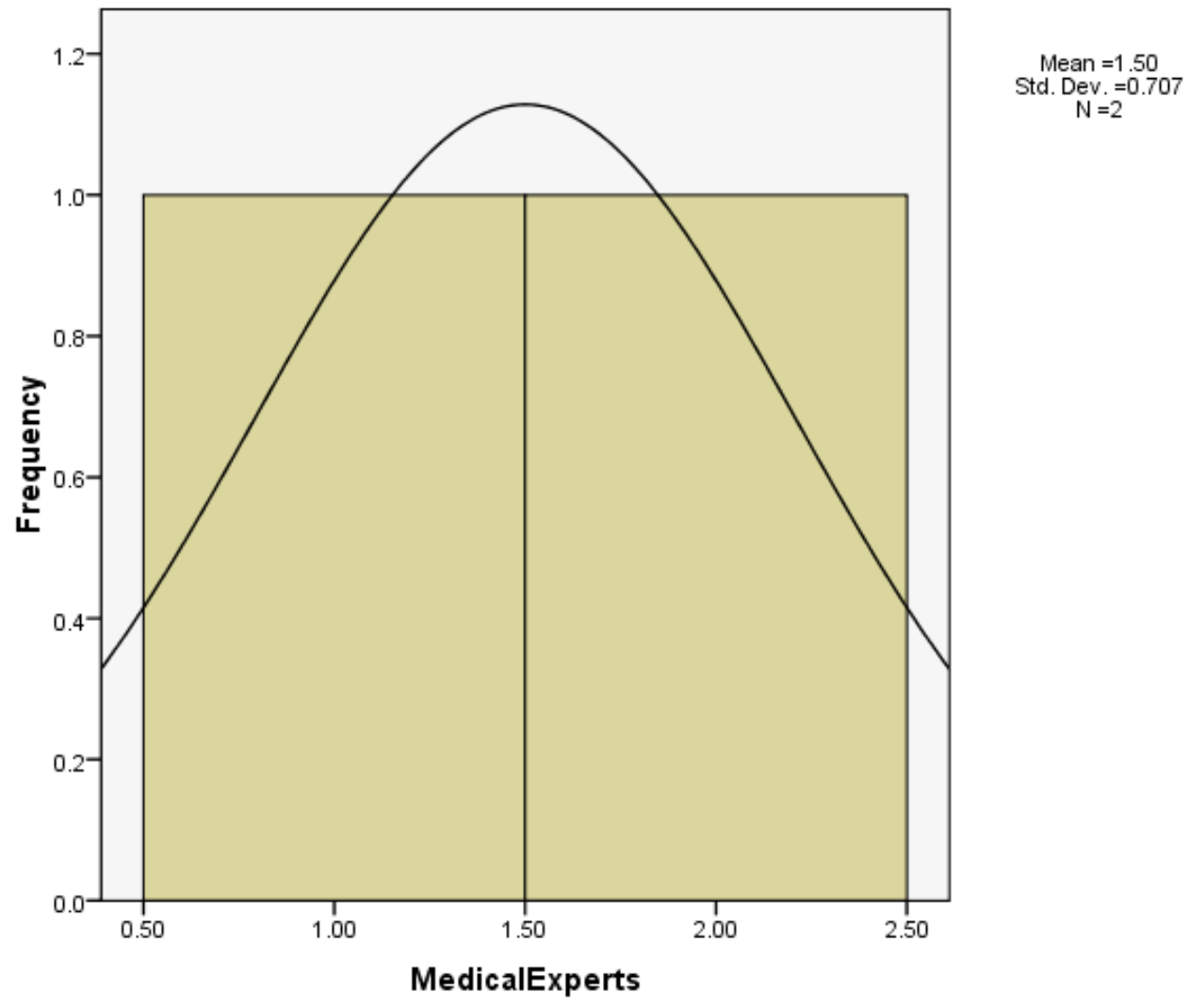

Figure 4. Medical Impact of COVID-19

\section{4- Discussion of Major Findings}

This part presents the discussion of significant findings. The discussion is divided into four major parts: an overview of COVID-19, legal impact, economic impact, and health impact. Each of these is explicitly discussed in the subsequent paragraphs.

First, concerning the overview of COVID-19, it is essential to reiterate that the responses from the interviewees among the legal, economic, and medical experts in Saudi Arabia confirmed that COVID-19 is not conjectural or speculative it is factual. The respondents' opinions demonstrated that COVID-19 is a global pandemic that started in Wuhan in China since 2019 [4]; its danger as the deadly virus has affected several countries throughout the world, including Saudi Arabia [18]. More specifically, the symptoms of the virus have been identified, such as shortness of breathing, loss of smell and taste, fever, among others. This position aligns with a number of studies that confirmed how dangerous and deadly COVID-19 is in recent times, as literature contends [3, 4, 32]. The spread of the virus has been identified as through close contact without proper protection or compliance with the protocols laid down by the World Health Organization (WHO). The participants also pointed out that Europe is witnessing second and third waves of COVID-19, which is in consonance with previous studies [14]. The findings demonstrated that the participants in the interview were aware of the danger of Covid-19, and it is acknowledged that the government has a vital role to play in creating awareness among citizenry regarding the contagious nature of the pandemic. This is in agreement with earlier 
research that posited that the government of a particular country has a significant role in curtailing the further spread of the pandemic through precautionary measures [19]. It should be reiterated that the study has established that Europe has been experiencing the second or third wave of COVID-19 spread. Hence, Saudi Arabia needs to further strengthen its mechanisms in preventing further spread. It has been stressed that COVID-19 has negative consequences the lockdown and social distancing as an integral part of preventive measures have eventually affected the Saudi citizens because they always like to partake in social gatherings and events. This position agrees with previous studies that the lockdown has undoubtedly affected the social life of the citizens in different parts of the world, including Saudi Arabia [20]. Furthermore, the impacts of COVID-19 have been mentioned by the participants in the interview among the legal, economic, and medical experts in the context of Saudi Arabia. It has been shown that Saudi Arabia has been very active with social activities, and surely, the pandemic of COVID-19 has affected social life and relationships such as gatherings, events, and social distancing. All the aforementioned are considered important mechanisms for preventing the spread of COVID-19 in the country, as literature posits [9, 21]. The pandemic of COVID-19 has led to different impediments such as working and learning online [22]. The challenge has further led to stress and anxiety, and the citizens have relied on the government in proffering solutions to the current challenges [20,23].

Second, pertaining to the legal impact of COVID-19 in Saudi, one of the participants in the interview posited that coronavirus undeniably has slowed down legal proceedings, and in the event of the current challenge of COVID-19, this undoubtedly may lead to the breach of contractual agreements and consequently lead to several litigations or settlements or reconciliations of business disagreement. As a result of the likelihood of this scenario, there is an inability to perform the contract between contractual parties, then provision of force majeure should be given prime importance as the literature says [13]. This assertion aligns with the existing literature that emphatically stresses the application of force majeure provision in the instance of an unforeseen eventuality like COVID-19 [10, 13, 24, 25]. Also, the legal team in the context of Saudi Arabia can look at the legal aspect of transnational work because since there are no transactions between contracting parties which may lead to issues or disagreements as many activities have been canceled. Additionally, one of the participants in the interview considered compliance with the preventive measures such as wearing of a face mask, maintaining social distance, etc. put in place by the government against the spread of COVID19 in the context of Saudi Arabia as legal aspect of the pandemic of coronavirus. Onwards, regarding legal impact of COVID-19, the respondents have noted the relevance of force majeure as a result of the phenomenon of the pandemic. This is due to the fact that the contractual parties might not be able to discharge their responsibilities due to the Pandemic of COVID-19. There is an established provision of force majeure which is a legal provision for the inability of a particular party to fulfil the agreement reached $[10,13]$. The participants have established that COVID-19 might trigger default between the contractual parties, and the provision of force majeure may be applicable in this scenario. Nonetheless, the default of contractual parities might be referred to as a breach of contract that might lead to litigation or settlement/reconciliation. This is so because several transactions have been cancelled due to the scenario of COVID-19. This assertion is in line with previous studies posited that COVID-19 has affected virtually all aspects of human endeavours including business contracts [7]. Undoubtedly, it is noted that a new legal framework would emerge as a result of the pandemic. This position is in line with the advocacy in Europe which Saudi Arabia can also derive great lessons from by having a legal framework in addressing the challenges of COVID-19 [11]. It should be reiterated that the interviewees perceived full enforcement of curfew in curtailing the further spread of COVID-19 is an integral part of the legal framework in addressing the impact of COVID-19. Nonetheless, failure to comply with the preventive measures should attract sanctions such as fines. It is also stressed that freedom of movement is an integral part of human rights, but it should be mentioned that nobody could claim personal liberty during the pandemic because it is detrimental to the collective survival of all the citizens in the country. Another important aspect of legal impact is that there is a need for a legal provision in protecting employees' interests, especially those that lay off by the employers [24]. With this position, Saudi Arabia is advocating for many countries by providing a legal framework in addressing many issues affected by COVID-19 [4].

Third, it must be stressed that the respondents or participants in the interview strongly uphold the view that the pandemic of coronavirus has affected the economic activities in Saudi Arabia, such as suspension of flight and other activities such as business, SMEs, tax, Zakat, Hajj, foreign exchange, oil etc. [26]. Similarly, there is the closure of businesses, suppression of old jobs, reduction of employees, loss of income and increase of poverty by some families. More specifically, it was reported that there was a budget deficit of 9 billion US Dollars in the first quarter of 2020 due to a decline in oil price caused by the pandemic of COVID-19 in the country. All the challenges mentioned above are the socio-economic impact of the COVID-19. Similarly, companies, especially Petrochemical industries, had drastic revenue reductions due to the decline in the international market price of petroleum [8]. It is noteworthy to say that, as a result of the reduction in the income of the citizens, it also affects the revenue generated from VAT by the government [27]. However, Saudi Arabia is optimistic about its vision 2030, then the country will definitely return back to economic growth as a result of the fact that there are economic responses to the outbreak of COVID-19, especially in the aspects of fiscal, monetary, and macroeconomics. Notably, the Saudi Arabian Ministry of Finance has been supportive of the economic recovery of the country. Additionally, International Monetary Fund (IMF) provides a policy tracker platform for different countries, including Saudi Arabia. Further still, the economic impact of COVID-19 is not disputable. The 
participants have further confirmed this fact because it is noted that the pandemic has affected the economic and financial status. This position aligns with previous studies that acknowledged the negative impact of COVID-19 on economic activities in different parts of the world [17]. It is not arguable to posit that there are mass lay-offs by some individuals due to the pandemic, which has affected the economic situation of many households. More importantly, most parents are hindered in providing essential needs to their children due to the negative impact of the pandemic on economic situation of the parents. More so, due to the loss of business, there is an increase in poverty for some families due to COVID-19. It is reiterated that Saudi Arabia has been trying to achieve Vision 2030 with specific focus on the socioeconomic development of the country. Nevertheless, the pandemic of COVID-19 has affected the efforts of the government in attaining Vision 2030. In spite of this challenge, the participants have shown optimism that Saudi Arabia shall return to economic growth in achieving Vision 2030. This position is in line with the contention of previous studies that the government sets guidelines for malls and the industrial sector to make the economic activities triumph [12]. The roles of Saudi in the economic development of the entire Gulf cannot be underestimated. However, during the pandemic, there has been fall in the oil price has undeniably affected the government finances in the country because oil is the major source of revenues for the government in spite of the fact the studies have advocated for economic diversification prior to the challenge of COVID-19 in the country. Saudi Arabia has been utilizing Islamic economic mechanisms such as Zakat to improve the citizens' socio-economic conditions. But the challenge of COVID-19 has affected the payment of Zakat because business activities were not flourishing due to the preventive measures put in place in curtailing the challenges of COVID-19. It is further buttressed that; many businesses have shut down their activities due to the problem of the pandemic. Also, it is necessary for the country to provide initiatives such as giving support to private sectors affected by the COVID-19 to resuscitate the business activities that have been closed operations. Hence, it is noteworthy to say that key economic policy is needed to address the pandemic challenge that limits the country's socio-economic activities.

Fourth, it should be reiterated that COVID-19 has brought about a burden in the healthcare system because there is insufficient knowledge and a higher level of anxiety about COVID-19, as the literature contends [28]. As a result of the proliferation in numbers of victims, there used to be a challenge and limitation or shortage of beds and medical equipment to treat the patients of COVID-19 [29]. Thus, the current challenge of COVID-19 has brought about improvement in hygiene among citizens in their daily activities as well as in public places like hospitals and banks [30]. However, one of the consequences of COVID-19 is that it has affected other patients suffering from other illnesses in getting necessary treatment because most of the illness nowadays is attributed to coronavirus. Then, most citizens with the healthy conditions may suffer loneliness and depression as social gatherings, and outdoor activities were not allowed. This assertion is in accordance with a number of studies that attributed anxiety and depression as medical or health impact of COVID-19 even among the health workers as literature explains [23]. Nonetheless, the government has been up and doing in ensuring that the consequences of COVID-19 are reduced [31]. As a result of the proactive step of the government, the Ministry of Health has been taking effective action in putting in place different preventive measures such as allocation of hospitals for treatment of patience which minimize the negative effect of COVID-19 [19, 32]. Indeed, pharmacists and health workers in the context of Saudi Arabia have been participating in different initiatives such as health promotion, counseling, and training on self-management and emergency preparedness [33]. More recently, the government has been trying to roll out vaccinations in the country to strengthen the citizens' preventive measures [30]. Therefore, it is important to say that citizens also need to support the government by adhering to all necessary protocols to prevent the further spread of COVID-19 to drastically reduce the disease's mortality rate, as the literature contends [17]. Onwards, it is not disagreeable to say that there is a negative impact of COVID-19 on the health sector in different parts of the world, including Saudi Arabia. More importantly, it should be said that the participants contend that COVID-19 has put pressure on the professionals, and it increases the costs of healthcare facilities. Nonetheless, Saudi Arabia has been making a tremendous effort in providing vaccination to curtail the health impact of COVID-19, which minimizes the pandemic's negative impact [23]. In this regard, the roles of the Ministry of Health cannot underestimate especially, when necessary precautionary measures are being put in place. It should be acknowledged further that various hospitals in Saudi Arabia have been striving to treat the victims of COVID-19. Moreover, the government has been committed to the development and launching of COVID-19 apps which provides healthcare services to the patients. Apart from this, it should be noted that there is need for new equipment and more beds for the patients in order to curtail the further spread of COVID-19 in the country. Similarly, pharmacists play professional roles in protecting the public from the scenario of COVID-19 in the country. Indeed, the said roles were done inform of enlightenment on the significance of healthcare service, patient counselling, training on emergency preparedness against COVID-19. All the aforementioned preventive measures are necessary to curtail the negative and long-term effects of COVID-19 such as loneliness and, depression among others. Onwards, it should be noted that preventive measures such as lockdown might be detriment to the health condition of the citizens. Due to the paramount importance of this need, the government has made provision for home services to the citizens in the form of palliatives, and medical attention has been strengthened. Lastly, the means obtained from the histogram demonstrated a need to pay meticulous attention to addressing the medical impact of COVID-19 as compared to the legal and economic impacts of COVID-19 in Saudi Arabia. 


\section{5- Conclusions}

This paper has empirically investigated various dimensions of the impacts of COVID-19 in the context of Saudi Arabia. The opinions of legal, economic, and medical experts were sought in this regard. The participants in the interview have established that the impacts of COVID-19 were not conjectural but factual. Specifically, the legal impact has been shown in the breach of contractual agreement, which might lead to litigation or reconciliation. Thus, the team of legal experts in Saudi Arabia has a paramount role to play in this regard. Also, the paper has demonstrated that there is an impact of COVID-19 on the socio-economic sphere in Saudi Arabia. It has been further stressed that COVID-19 caused a pathetic burden on the healthcare system in Saudi Arabia and other parts of the world. There are limitations or shortages of beds and medical equipment to treat the patients of COVID-19. The limitation of this paper lies in the few numbers of participants among legal, health, and economic experts involved in the interview. However, the paper has provided substantial direction for the future and further research exploring the impacts of COVID-19 in the country to address the impacts from multidimensional aspects.

The following recommendations are made:

- Precautionary measures in preventing the further spread of the COVID-19 pandemic are paramount in Saudi Arabia to safeguard the lives of the citizens.

- There is need to address the legal aspect of transnational work because since there are no transactions between contracting parties, it may lead to issues or disagreements between contracting parties as many activities have been canceled.

- Also, there is a need to enhance the economic activities of Saudi Arabia, especially in the aspects of business, SMEs, tax, Zakat, Hajj, foreign exchange, oil etc., to recapitulate from the economic challenge emanating from COVID-19.

- The government should increase healthcare services such as beds and equipment for treating the victims of COVID-19 and come up with initiatives such as health promotion, counseling, and training on self-management and emergency preparedness against COVID-19 in the country.

\section{6- Declarations}

\section{6-1-Author Contributions}

Conceptualization, Y.J.A. and E.C.; methodology, Y.J.A and S.H.; software, M.D.; validation, Y.J.A., E.C. and S.H.; formal analysis, M.D.; investigation, S.H.; resources, E.C.; data curation, Y.J.A; writing - original draft preparation, Y.J.A; writing - review and editing, Y.J.A. and M.D.; supervision, E.C.; funding acquisition, Y.J.A. All authors have read and agreed to the published version of the manuscript.

\section{6-2-Data Availability Statement}

The data presented in this study are available in the article.

\section{6-3- Funding}

This work was supported by the Governance and Policy Design Research Lab (GPDRL) of Prince Sultan University.

\section{6-4- Conflicts of Interest}

The authors declare that there is no conflict of interests regarding the publication of this manuscript. In addition, the ethical issues, including plagiarism, informed consent, misconduct, data fabrication and/or falsification, double publication and/or submission, and redundancies have been completely observed by the authors.

\section{7- References}

[1] Li, Q., Guan, X., Wu, P., Wang, X., Zhou, L., Tong, Y., Ren, R., Leung, K. S. M., Lau, E. H. Y., Wong, J. Y., Xing, X., Xiang, N., Wu, Y., Li, C., Chen, Q., Li, D., Liu, T., Zhao, J., Liu, M., ... Feng, Z. (2020). Early Transmission Dynamics in Wuhan, China, of Novel Coronavirus-Infected Pneumonia. New England Journal of Medicine, 382(13), $1199-1207$. doi:10.1056/nejmoa2001316.

[2] Zhu, N., Zhang, D., Wang, W., Li, X., Yang, B., Song, J., Zhao, X., Huang, B., Shi, W., Lu, R., Niu, P., Zhan, F., Ma, X., Wang, D., Xu, W., Wu, G., Gao, G. F., \& Tan, W. (2020). A Novel Coronavirus from Patients with Pneumonia in China, 2019. New England Journal of Medicine, 382(8), 727-733. doi:10.1056/nejmoa2001017.

[3] Benkouiten, S., Al-Tawfiq, J. A., Memish, Z. A., Albarrak, A., \& Gautret, P. (2019). Clinical respiratory infections and pneumonia during the Hajj pilgrimage: A systematic review. Travel Medicine and Infectious Disease, 28, 15-26. doi:10.1016/j.tmaid.2018.12.002. 
[4] Chan, J. F. W., Kok, K. H., Zhu, Z., Chu, H., To, K. K. W., Yuan, S., \& Yuen, K. Y. (2020). Genomic characterization of the 2019 novel human-pathogenic coronavirus isolated from a patient with atypical pneumonia after visiting Wuhan. Emerging Microbes and Infections, 9(1), 221-236. doi:10.1080/22221751.2020.1719902.

[5] Nishiura, H., Jung, S. M., Linton, N. M., Kinoshita, R., Yang, Y., Hayashi, K., Kobayashi, T., Yuan, B., \& Akhmetzhanov, A. R. (2020). The extent of transmission of novel coronavirus in Wuhan, China, 2020. Journal of Clinical Medicine, 9(2), 330. doi:10.3390/jcm9020330.

[6] Ebrahim, S. H., \& Memish, Z. A. (2020). COVID-19: preparing for superspreader potential among Umrah pilgrims to Saudi Arabia. The Lancet, 395(10227), e48. doi:10.1016/S0140-6736(20)30466-9.

[7] Ameen, F., Amna, T., Alghamdi, A. A. A., AlKahtani, M. D. F., \& AlYahya, S. A. (2020). Covid-19 pandemic outburst in Saudi Arabia: A glimpse. Saudi Journal of Biological Sciences, 27(12), 3547-3552. doi:10.1016/j.sjbs.2020.07.026.

[8] Shittu, R. (2019). Economic impact of overweight on the labour market. Stears Bus, 1-5. doi:10.1787/c6d0a63e-en.

[9] Ebrahim, S. H., \& Memish, Z. A. (2020). COVID-19 - the role of mass gatherings. Travel Medicine and Infectious Disease, 34, 101617. doi:10.1016/j.tmaid.2020.101617.

[10] Ahmad, A.-B. H., Ghadas, Z. A. A., Asuhaimi, F. A., \& Udin, N. M. (2018). The Principle of Force Majeure in Shariah: A Special Reference to Saudi Contract. Turkish Online Journal of Design Art and Communication, 8(SEPT), $1097-1106$. doi:10.7456/1080sse/150.

[11] Harris, Dan. "Coronavirus Legal Issues Around the World, Part 1: Employment Law Issues.” Harris Bricken. Harris Bricken, 2020. Available online: https://harrisbricken.com/chinalawblog/coronavirus-legal-issues-around-the-world-part-1-employmentlaw-issues/ (accessed on October 2021).

[12] Khalid, Tuqa. "Coronavirus: Saudi Arabia Sets Guidelines for Malls, Industrial Sector, as It Reopens.” Al Arabiya, 2020. Available online: https://english.alarabiya.net/coronavirus/2020/05/29/Coronavirus-Saudi-Arabia-sets-guidelines-for-mallsindustrial-sector-as-it-reopens (accessed on June 2021).

[13] Salameh, Emad, Abubaker Jeeballah, and Mohammed AlOthman. "COVID-19: Force Majeure Under Saudi Law \& Shari' ah |." Al Tamimi \& Company. Al Tamimi \& Company, 2020. Available online: https://www.tamimi.com/law-update-articles/covid19-force-majeure-under-saudi-law-and-shariah/ (accessed on October 2021).

[14] World Health Organization. "Coronavirus Disease (COVID-19) Pandemic," Available online: https://www.who.int/emergencies/diseases/novel-coronavirus-2019 (accessed on June 2021).

[15] Khatatbeh, M. (2020). Efficacy of Nationwide Curfew to Encounter Spread of COVID-19: A Case From Jordan. Frontiers in Public Health, 8, 394. doi:10.3389/fpubh.2020.00394.

[16] ilton, Tommy. "Coronavirus: Saudi Arabia Now Has over 100,000 COVID-19 Cases.” Al Arabiya English. Al Arabiya English, 2020. Available online: https://english.alarabiya.net/coronavirus/2020/06/07/Coronavirus-Saudi-Arabia-now-has-more-than100-000-COVID-19-cases- (accessed on June 2021).

[17] Ebrahim, S. H., Ahmed, Q. A., Gozzer, E., Schlagenhauf, P., \& Memish, Z. A. (2020). Covid-19 and community mitigation strategies in a pandemic. The BMJ, 368. doi:10.1136/bmj.m1066.

[18] World Health Organization. "Coronavirus Disease 2019 Situation Report - 187.” A \& A Practice 14, no. 6 (2020): e01218e01218. Available online: https://www.who.int/docs/default-source/coronaviruse/situation-reports/20200407-sitrep-78-covid19.pdf (accessed on June 2021).

[19] Alshammari, T. M., Alenzi, K. A., Alnofal, F. A., Fradees, G., \& Altebainawi, A. F. (2021). Are countries' precautionary actions against COVID-19 effective? An assessment study of 175 countries worldwide. Saudi Pharmaceutical Journal, 29(5), $391-409$. doi:10.1016/j.jsps.2021.03.011.

[20] Alsaif, B., Elhassan, N. E. E., Itumalla, R., Ali, K. E., \& Alzain, M. A. (2021). Assessing the level of awareness of covid - 19 and prevalence of general anxiety disorder among the hail community, kingdom of saudi arabia. International Journal of Environmental Research and Public Health, 18(13). doi:10.3390/ijerph18137035.

[21] "Saudi Locks down Qatif as Coronavirus Surges in the Gulf." Al Jazeera News, 2020. Available online: https://www.aljazeera.com/news/2020/03/saudi-locks-qatif-coronavirus-surges-gulf-200308142809697.html (accessed on June 2021).

[22] Alshehri, Y. A., Mordhah, N., Alsibiani, S., Alsobhi, S., \& Alnazzawi, N. (2020). How the Regular Teaching Converted to Fully Online Teaching in Saudi Arabia during the Coronavirus COVID-19. Creative Education, 11(07), 985-996. doi:10.4236/ce.2020.117071.

[23] Abolfotouh, M. A., Almutairi, A. F., Banimustafa, A. A., \& Hussein, M. A. (2020). Perception and attitude of healthcare workers in Saudi Arabia with regard to Covid-19 pandemic and potential associated predictors. BMC Infectious Diseases, 20(1), 1-10. doi:10.1186/s12879-020-05443-3. 
[24] Sami, Omar. “A Few Legal Insights: Manager Liabilities in Saudi Arabia during Covid-19.” Rödl \& Partner. Rödl \& Partner, 2020. Available online: https://www.roedl.com/insights/saudi-arabia-legal-insights-manager-liabilities-covid-19 (accessed on October 2021).

[25] Urquhart, Quinn Emanuel, and Sullivan. “COVID-19 and Legal Issues in Saudi Arabia.” International Comparative Legal Guide. International Comparative Legal Guide, 2020. Available online: https://iclg.com/briefing/12349-covid-19-and-legal-issues-insaudi-arabia (accessed on October 2021).

[26] “Saudi Arabia Suspending Domestic Flights, Mass Land Transport in Fight against COVID-19.” Arab News, 2020. Available online: https://www.arabnews.com/node/1644101/saudi-arabia (accessed on June 2021).

[27] Amlôt, Matthew. “Jobs, Health Priority in Coronavirus Spending Cuts, VAT Hike: Saudi Finance Minister.” Al Arabiya English. Al Arabiya English, 2020. Available online: https://english.alarabiya.net/coronavirus/2020/05/11/Jobs-health-priority-incoronavirus-spending-cuts-VAT-hike-Saudi-Finance-Minister (accessed on June 2021).

[28] Sallam, M., Dababseh, D., Yaseen, A., Al-Haidar, A., Ababneh, N. A., Bakri, F. G., \& Mahafzah, A. (2020). Conspiracy beliefs are associated with lower knowledge and higher anxiety levels regarding covid-19 among students at the university of Jordan. International Journal of Environmental Research and Public Health, 17(14), 1-15. doi:10.3390/ijerph17144915.

[29] Alhamlan, F. S., Majumder, M. S., Brownstein, J. S., Hawkins, J., Al-Abdely, H. M., Alzahrani, A., Obaid, D. A., Al-Ahdal, M. N., \& BinSaeed, A. (2017). Case characteristics among Middle East respiratory syndrome coronavirus outbreak and nonoutbreak cases in Saudi Arabia from 2012 to 2015. BMJ Open, 7(1). doi:10.1136/bmjopen-2016-011865.

[30] Albogami, Y., Alkofide, H., \& Alrwisan, A. (2021). Covid-19 Vaccine Surveillance in Saudi Arabia: Opportunities for Realtime Assessment. Saudi Pharmaceutical Journal, 29(8), 914-916. doi:10.1016/j.jsps.2021.07.005.

[31] Obeid, D. A., Alhamlan, F. S., Al-Qahtani, A. A., \& Al-Ahdal, M. N. (2020). Containment of COVID-19: The unprecedented response of Saudi Arabia. Journal of Infection in Developing Countries, 14(7), 699-706. doi:10.3855/jidc.13203.

[32] Alshammari, T. M., Altebainawi, A. F., \& Alenzi, K. A. (2020). Importance of early precautionary actions in avoiding the spread of COVID-19: Saudi Arabia as an Example. Saudi Pharmaceutical Journal, 28(7), 898-902. doi:10.1016/j.jsps.2020.05.005.

[33] Binsaleh, N. K., Bazaid, A. S., Aldarhami, A., Sherwani, S., \& Althomali, O. W. (2021). Awareness and practice of covid-19 precautionary measures among healthcare professionals in Saudi Arabia. Journal of Multidisciplinary Healthcare, 14, 15531560. doi:10.2147/JMDH.S317908. 